associated with other genital infections such as gonorrhoea or trichomoniasis.

In the absence of a safe and effective systemic antifugal agent treatment depends on the use of locally acting preparations. The principle is to apply the preparation to all the affected mucosal and skin areas for long enough to eliminate all the fungus and spores and at the same time to take measures to prevent reinfection by a sexual partner or from the patient's own gastrointestinal tract or elsewhere. Any predisposing factor should be eliminated if possible.

For years now the antifungal antibiotic, nystatin, has been the mainstay of treatment, used as vaginal pessaries, ointment, or cream. Oral tablets are available for gastrointestinal infections. Many other antifungal agents are incorporated into pessaries or ointments. Recently it has been suggested that better immediate and long-term results are obtained with ointments, ${ }^{5}$ though many patients complain that they are messy to use and difficult to apply even with an applicator. There is no evidence that the fungus develops any resistance to antifungal agents (with the one exception of amphotericin), and it is extremely difficult to assess whether any of the locally acting antifungal preparations is more effective than others; relapses are frequent and the treatment is far from satisfactory. In the long term a major advance in the treatment of candidosis will come only from the discovery of a safe and effective systemic agent, just as the treatment of trichomoniasis was revolutionised by the oral preparation metronidazole.

1 Oriel, J D, et al, British Medical fournal, 1972, 4, 761.

${ }^{2}$ Hurley, R, et al, fournal of Obstetrics and Gynaecology of the British Commonwealth, 1973, 80, 252.

${ }^{3}$ Catterall, R D, British fournal of Venereal Diseases, 1971, 47, 45.

${ }^{4}$ Department of Health and Social Security, Annual Report of the Chief Medical Officer for the Year 1974. On the State of the Public Health. London, HMSO, 1975.

${ }^{5}$ Morese, K. N, New York State Fournal of Medicine, 1975, 75, 1443.

\section{Rib pain}

Pain in the chest is a source of anxiety to both patient and doctor so long as its cause remains uncertain. Probably the most common cause is trauma to the rib cage from sporting activities, accidents, falls, or assault. Careful history, examination, and investigation will confirm the diagnosis but not always the severity of the injury- $x$-ray films often show only about half the rib fractures that actually exist, given what is found at necropsy. ${ }^{1}$ Complications may include haemothorax, pneumothorax, or the paradoxical movement of a "stove-in" chest, with respiratory embarrassment. Less commonly, where the uppermost ribs are fractured, there may also be a fracture of the clavicle and damage to the brachial plexus or the subclavian artery. Blunt trauma to the anterior chest wall may result in a fractured sternum and may cause mediastinal complications such as a tear in the arch of the aorta or cardiac contusion or tamponade. The first warning of these complications may be widening of the mediastinal shadow in the $x$-ray film, dysrhythmias or ischaemic changes on the ECG, or changes in central venous pressure respectively. A flexion fracture of the midthoracic spine may be seen in association with a fracture of the sternum and should therefore be considered in asking for specific radiological investigations.

The treatment of pain from simple rib fractures is oftengiven less consideration than the patient would like. Treatment should match individual circumstances. Strapping (applied in expiration) is usually best reserved for the young and active, whose lungs can accommodate the immobilisation. A simple test of the likely value of strapping is the relief given by the patient's own manual support of the injured area. In elderly patients restriction of respiratory movements may precipitate stasis and infection, so that strapping is contraindicated and analgesics are the treatment of choice. Valuable but less often employed is infiltration of the fracture site or block of the intercostal nerves by injection of a local anaesthetic.

$\mathrm{Rib}$ pain from obvious trauma causes little problem in diagnosis, but other mechanical causes of rib pain may be more puzzling. The cough fracture is well recognised, but less familiar is the pain caused by increased mobility of the anterior ends of the lower ribs. Described variously as the rib-tip syndrome, ${ }^{2}$ slipping rib, ${ }^{3}$ clicking rib, ${ }^{4}$ or nerve nipping at the intercostal margin, ${ }^{5}$ this condition may cause severe pain. It may be associated with a history of trauma and is usually described as a sharp pain related to movement or occasionally as a burning pain; it may be localised at the anterior end of the ribs or may radiate to the back.

$\mathrm{McBeath}$ and Keene recently investigated ${ }^{2}$ the anatomy of the anterior ends of the ribs and found that the eighth, ninth, and tenth ribs are attached anteriorly only to each other and by loose fibrous tissue. Trauma may make one of these ribs more mobile, and its movement may be palpable to the examining fingers and may result in direct pressure on the intercostal nerve. Radiological investigation will not disclose the condition, but manual pressure should reproduce the pain. The diagnosis of rib-tip syndrome should therefore be made on the history and findings at examination. Once it is confirmed, reassurance may be sufficient for the over-anxious, while infiltration with local anaesthetic and steroid preparations may relieve troublesome symptoms. In those with severe or recurring pain surgical excision of the rib tip offers a permanent cure.

Tietze's disease is another less common cause of rib pain, characterised by a painful non-suppurative swelling of the second or third costal cartilage: again the chest $x$-ray film is normal. Treatment may vary from reassurance to the application of local heat or the local injection of hydrocortisone.

Radiological examination of a painful rib swelling may occasionally show a benign or malignant tumour. Benign tumours, often symptomless, rarely cause pathological fractures; they include chondromas, multiple exostoses, solitary myeloma, and fibrous dysplasia, and in the first removal is usually advised because there is a risk of malignant change. Primary malignant tumours are rare, and the most likely is a chondrosarcoma. Typically, metastases in the rib are associated with a primary lesion in the lung or breast, though other primary sites may be concerned. Such secondary deposits are almost invariably painful and tender.

Pain in the rib cage may also be caused by a neurofibroma affecting the intercostal nerve or a ganglioneuroma arising from the sympathetic chain. Such tumours may cause mechanical and neurological symptoms from pressure, but more often than not they are symptomless and single.

Finally the rib cage may encompass a unilateral or bilateral extra member, the cervical rib, a congenital fibrous or bony extension from the seventh cervical vertebra. Cervical ribs rarely cause local symptoms: more common are neurological features in the arm varying from pain and paraesthesiae from pressure on the brachial plexus to the less frequent vasomotor or vascular symptoms. In both instances detailed examination, including the effect of shoulder movement and mapping the distribution of neurological changes, will narrow the diagnostic 
spectrum from the other possibilities that must be considered -cervical disc lesions and spondylolisthesis, carpal tunnel syndrome, ulna nerve compression at the elbow, tumours at the thoracic inlet, subclavian aneurysm, Raynaud's disease, and more general neurological or muscular diseases.

${ }^{1}$ London, P S, A Practical Guide to the Care of the Injured. Edinburgh, Livingstone, 1967.

${ }^{2}$ McBeath, A A, and Keene, J S, Fournal of Bone and foint Surgery, 1975, 57 A, 795.

${ }^{3}$ Davies-Colley, R, British Medical fournal, 1922, 1, 432.

${ }^{4}$ Mynors, J M, Lancet, 1973, 1, 674.

${ }^{5}$ Stevenson, F H, Lancet, 1951, 2, 969.

\section{Liquor licensing and public health}

The Departmental Committee on Liquor Licensing (the Erroll Committee), published its report ${ }^{1}$ in December 1972, making a number of recommendations for liberalising the licensing laws. Among these were suggestions that justices should have their power to refuse new licences much curtailed; that the legal drinking age should be lowered; that children should more easily be allowed with their parents into public drinking places; that alcohol should be on sale in more and different kinds of premises (with a view towards establishing a Continental style of café pub); and that licensing hours should be extended. Public health reactions to the report were unfavourable. Concern was expressed that the health and welfare implications had been passed over too lightly by the committee, and we commented that the report was proposing a gamble with the nation's health. ${ }^{2}$ As for the reactions of the public, a Gallup Poll showed that most were against lowering the drinking age, extending the licensing hours, and allowing children into bars. ${ }^{3}$

The Erroll Report at least served a valuable purpose by stimulating a debate-one outcome of which should have been a sharpened official and public awareness of the possibility that any tinkering with the nation's system of drink control might adversely affect the nation's drinking problems. The expectation was that the report would not be put into effect: but unwise steps may yet be taken with the introduction of a private member's Bill which will be given its second reading on 27 February. ${ }^{4}$ The Home Office cannot be seen as entirely neutral, for it has provided help in drafting the Bill. The three elements which it selects out of the original package relate to extension of licensing hours; admission of children to licensed premises and registered clubs; and a complex technical matter (repeal of Section 76 (5) of the Licensing Act of 1964) which would in effect make it easier and perhaps cheaper for places of entertainment to sell drink to a late hour.

Has anything happened over the last three years which should modify the health opinion? In an area which has traditionally attracted passion it is essential that any health stand should be based on a willingness to review new data as they become available. It happens that since the Erroll Report was published a detailed review of public health aspects of alcohol control policies has been prepared by the World Health Organisation in conjunction with the Finnish Foundation for Alcohol Studies and the Addiction Research Foundation of Ontario. ${ }^{5}$ The following passage is to be found in the introduction to that monograph: ". . . our main argu- ment is well substantiated: changes in the overall consumption of alcoholic beverages have a bearing on the health of the people in any society. Alcohol control measures can be used to limit consumption: thus, control of alcohol availability becomes a public health issue."

The WHO document readily admits the difficulty of forming any final or universal view of the likely impact of change in any one regulation without at the same time looking at a host of interacting social and fiscal factors. Study of legislative change does not lend itself to the neat methods of the controlled trial. There might be circumstances in which legislation of the sort proposed by the current Bill would be innocuous, but it seems more likely that each element in the three-part package will in some small way lead to greater consumption and so greater health risks. The authority of this recent monograph supports the accuracy of the original assertion that to liberalise our liquor laws is a gamble: no one can guarantee the danger but neither is anyone in a position to say that no harm would result.

There is nothing to argue that now is a better moment than three years ago to take even a restricted gamble. Offences of public drunkenness, drunk driving offences, and hospital admissions for alcoholism are all at their highest levels for many years. Certainly in recent times the public has not seemed unduly handicapped in its access to drink: over the four years to the end of 1974 national annual consumption of alcohol rose by $37 \%$, an increase of 19 million gallons of absolute alcohol. ${ }^{6}$

The present Bill is more modest than the original Erroll proposals but none the less represents an erosion of public health defences against one of the country's major health and social problems. For the present there should be a moratorium on all measures which make drink more available.

1 Report of the Departmental Committee on Liquor Licensing. London, HMSO, 1972.

2 British Medical fournal, 1972, 4, 625.

${ }^{3}$ Daily Telegraph, 27 December 1972.

4 Hansard, 17 December 1975, col 1396.

${ }^{5}$ Bruun, K, et al, Alcohol Control Policies in Public Health Perspective. Helsinki, Finnish Foundation for Alcohol Studies, 1975.

${ }^{6}$ Health Education Council, 1975, Fact sheet RP/6/1.

\section{Programming in human growth}

Two major areas of ignorance in nutrition are the relative contributions of genetics and environment in determining physique at different ages and the long-term influence of physique at one age on physique at another. Essentially the problem is one of data collection, since longitudinal studies are needed to answer both these questions, but they are in short supply. Nevertheless, there is a growing body of information from which a synthesis may be made of some of the genetic, prenatal, and postnatal factors that influence body habitus.

Recently, for instance, Fish et al ${ }^{1}$ collected data on whether extremes of body build at birth were predictive of leanness and obesity at 4 and 7 years of age. Unfortunately, a peripheral measure of body fat was used (a ratio of weight to height), but neonates who were either extremely lean or extremely obese tended to stay the same over the years, though the 